\title{
Metástase Vaginal como Manifestação Inicial de Carcinoma de Células Renais
}

\author{
Vaginal Metastasis as Initial Manifestation of Renal Cell Carcinoma
}

\author{
Marília Buenos Aires Cabral Tavares', Amanda Correia da Paz', Adriano Leite Camilo da Silva', Rodrigo Beserra Sousa', \\ João Rubens Agostinho Rolim', Carolina Buenos Aires Cabral Tavares² e Sabas Carlos Vieira ${ }^{3}$
}

\section{Resumo}

A ocorrência de metástases de carcinoma de células renais para a vagina é rara. Ocorre principalmente em mulheres na pós-menopausa e o principal fator prognóstico é se essa metástase apresenta-se ou não isolada. Poucos casos foram relatados na literatura mundial e a maioria destes envolve metástases originadas no rim esquerdo. Os autores apresentam um caso de metástase vaginal de carcinoma de células renais em uma paciente de 53 anos de idade cuja apresentação clínica inicial foi de uma massa pediculada com bordas irregulares na parede posterior da vagina. Realizou-se a retirada cirúrgica da lesão que revelou tratar-se de adenocarcinoma de células claras. A ultrasonografia abdominal evidenciou presença de massa incidental no rim esquerdo e foi realizada a nefrectomia deste rim. O estudo imunoistoquímico realizado demonstrou tratar de lesão neoplásica primária do rim com metástase para a vagina. A paciente, então, recebeu radioterapia adjuvante na vagina e na pelve. Após oito meses do início do tratamento, realizou-se imunoterapia com interferon 2 devido ao aparecimento de metástase também para o fígado. A paciente encontra-se viva 17 meses após a cirurgia.

Palavras-chave: Metástase vaginal, Carcinoma de células renais, Adenocarcinoma de células claras

${ }^{1}$ Estudante de Medicina da Universidade Federal do Piauí (UFPI)

${ }^{2}$ Residente de Ginecologia e Obstetrícia - Universidade Federal do Ceará (UFC)

${ }^{3}$ Doutorando e Mestre em Ciências Médicas (Unicamp). Professor de Cirurgia e Oncologia da UFPI. Especialista em Cancerologia. Cirurgião Oncológico do Hospital São Marcos

Trabalho realizado no Hospital São Marcos - Universidade Federal do Piauí (UFPI)

Endereço para correspondência: Sabas Carlos Vieira. Rua Félix Pacheco 2159, Sala 305 - Centro - Teresina (PI), Brasil - CEP: 64001-160.

E-mail: sabasvieira@uol.com.br 


\section{INTRODUÇÃO}

De todas as neoplasias ginecológicas, os tumores vaginais representam de $1 \%$ a $2 \%{ }^{1}$. Somente $5 \%$ de todas as neoplasias vaginais correspondem a tumor primário, sendo o tipo histológico mais freqüente o adenocarcinoma. A maioria é metastático ${ }^{2}$. O carcinoma de células renais apresenta um comportamento biológico variável com disseminação imprevisível, longo período de latência, metástases solitárias, demonstrando uma heterogeneidade do processo neoplásico ${ }^{3,4}$. A ocorrência de metástase de carcinoma de células renais para a vagina é rara, embora esta seja uma das formas de apresentação de carcinoma renal ${ }^{3}$. Há poucos casos como estes relatados na literatura. Tarraza et al. revisaram 68 casos até $1983^{5}$, enquanto Bozaci et al. revisaram desde então 23 casos até $2005^{2}$.

Relatamos um caso de carcinoma de células renais com metástase vaginal, bem como apresentamos uma revisão da patologia e a conduta frente a essa apresentação clínica incomum. Também apresentamos resumidamente os 24 casos descritos dessa patologia desde 1983 (Tabela 1).

\section{RELATO DO CASO}

Paciente do gênero feminino, 53 anos de idade, apresentou sangramento vaginal, mal-estar e indisposição. Ao exame físico, observou-se uma massa pediculada de bordas irregulares na parede posterior da vagina e que media $1,5 \times 1,0 \mathrm{~cm}$. Realizou-se a retirada cirúrgica dessa lesão, que revelou tratar-se de carcinoma de células claras. Foi realizada uma ultra-sonografia abdominal, que revelou massa incidental no rim esquerdo. O hemograma e a cintilografia óssea foram normais. A paciente submeteu-se à nefrectomia esquerda e, à macroscopia, observou-se no terço médio uma tumoração medindo $6,0 \times 6,0 \mathrm{~cm}$. O exame histopatológico demonstrou carcinoma de células transicionais com extensa área de necrose de coagulação, invasão capsular, índice mitótico moderado e infiltração da pelve renal. $\mathrm{O}$ estudo imunoistoquímico realizado mostrou características de coloração da lesão vaginal idênticas às do tumor primário com um citoplasma fortemente corado pela vimentina, áreas focais do citoplasma corado com citoceratina de baixo peso molecular e membrana difusamente corada com CD10 (Figuras 1 e 2). A conclusão diagnóstica foi de lesão neoplásica primária do rim com metástase para a vagina.

A paciente, então, recebeu radioterapia adjuvante na vagina e na pelve. Oito meses após o inicio do tratamento, referiu dor em hipocôndrio direito e ao ultra-som abdominal superior apresentou pequeno nódulo $(1,11 \mathrm{~cm})$ no lobo hepático direito de aspecto ecográfico compatível com metástase e pequenos pólipos na vesícula biliar. Iniciou-se imunoterapia com interferon 2. A paciente encontra-se viva 17 meses após a cirurgia.

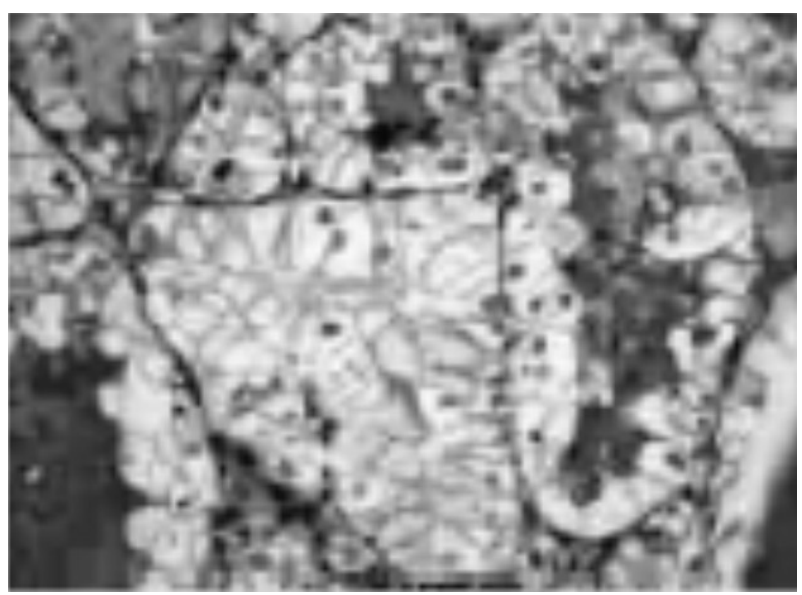

Figura 1. Imunoistoquímica da vagina: Carcinoma de células claras com padrão focal papilífero consistente com carcinoma renal metastático

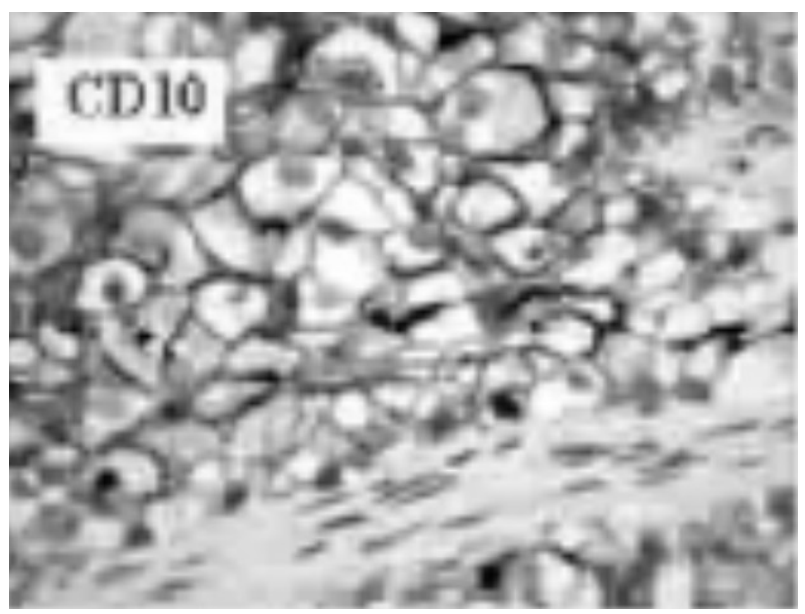

Figura 2. Imunoistoquímica do rim: carcinoma de células claras com padrão focal papilífero

\section{DISCUSSÃO}

Mais de 90\% dos adenocarciomas vaginais são metastáticos provenientes principalmente da cérvice, endométrio, cólon ou ovário ( $65 \%$ dos casos), menos freqüentemente o tumor primário se origina do pâncreas, estômago ou rim ${ }^{3}$. O adenocarcinoma primário de vagina é mais freqüente em mulheres jovens com exposição do útero ao dietisbestrol, enquanto a metástase do carcinoma de células renais é mais freqüente em mulheres na pós-menopausa ${ }^{1,2}$. Pouco mais de 90 casos de carcinoma de células renais com metástase vaginal 
Tabela 1. Relatos de metástase vaginal de carcinoma de células renais (CCR) desde 1983

\begin{tabular}{|c|c|c|c|c|c|}
\hline Autor & Idade & Rim envolvido & $\begin{array}{l}\text { Lado da } \\
\text { vagina } \\
\text { envolvido }\end{array}$ & Época da metástase & $\begin{array}{c}\text { Sintoma da } \\
\text { CCR }\end{array}$ \\
\hline O'Reilly & 48 & Direito & Anterior & $\begin{array}{c}\text { Conc. com TR e } \\
\text { metástase recorrente } 3 \\
\text { meses após nefrectomia }\end{array}$ & $\begin{array}{c}\text { Descarga } \\
\text { vaginal e nódulo }\end{array}$ \\
\hline Sharma & 52 & Esquerdo & Esquerdo & 3 meses antes do TR & SV, hematúria \\
\hline Lipman & 69 & Direito & Anterior & 1 ano depois do TR & $?$ \\
\hline Serrata & 60 & Esquerdo & Anterior & 3 meses depois do TR & $?$ \\
\hline $\begin{array}{l}\text { Ovesen and } \\
\text { Gersstenberg }\end{array}$ & 51 & Esquerdo & Esquerdo & Conc. com TR & $\begin{array}{l}\text { Massa vaginal } \\
\text { incidental }\end{array}$ \\
\hline Torne & 44 & Esquerdo & Esquerdo & Conc. com TR & $\begin{array}{c}\text { Sangramento } \\
\text { pós-coito; massa } \\
\text { vaginal }\end{array}$ \\
\hline Yokoyama & 50 & Direito & Anterior & 3 meses depois do TR & $\begin{array}{l}\text { Massa vaginal } \\
\text { incidental }\end{array}$ \\
\hline Bouyounes & 47 & Esquerdo & - & Conc. com TR & $\begin{array}{c}\text { Sangramento } \\
\text { pós-coito }\end{array}$ \\
\hline \multirow[t]{4}{*}{ Tarraza } & 77 & Esquerdo & $\begin{array}{l}\text { Ântero- } \\
\text { posterior }\end{array}$ & Conc. com TR & $\begin{array}{l}\text { Sangramento } \\
\text { pós-coito }\end{array}$ \\
\hline & 65 & Esquerdo & Anterior & Conc. com TR & $\begin{array}{l}\text { Sangramento } \\
\text { pós-coito }\end{array}$ \\
\hline & 69 & Esquerdo & Esquerdo & Conc. com TR & $\begin{array}{l}\text { Sangramento } \\
\text { pós-coito }\end{array}$ \\
\hline & 82 & Direito & $\begin{array}{l}\text { Ântero- } \\
\text { posterior }\end{array}$ & Conc. com TR & $\begin{array}{l}\text { Sangramento } \\
\text { pós-coito }\end{array}$ \\
\hline Seseke & 75 & Esquerdo & - & $\begin{array}{l}6 \text { meses depois do TR e } \\
\text { recorrente } 12 \text { meses } \\
\text { após cirurgia }\end{array}$ & Massa renal \\
\hline \multirow[t]{4}{*}{ Abraham } & 55 & Esquerdo & Esquerdo & Conc. com TR & SV \\
\hline & 65 & Direito & Posterior & Conc. com TR & SV \\
\hline & 62 & Esquerdo & Esquerdo & Conc. com TR & SV \\
\hline & 67 & Esquerdo & $\begin{array}{l}\text { Ântero- } \\
\text { posterior }\end{array}$ & Conc. com TR & $\begin{array}{l}\text { Perda de peso, } \\
\text { função renal } \\
\text { anormal }\end{array}$ \\
\hline Queiroz & 45 & Esquerdo & Esquerdo & Conc. com TR & SV \\
\hline Wyczólkowski & 70 & Esquerdo & Posterior & Conc. com TR & SV \\
\hline Pruthi & 52 & Direito & Direito & 10 anos após TR & $\begin{array}{l}\text { Massa renal } \\
\text { incidental }\end{array}$ \\
\hline \multirow[t]{2}{*}{ Griffin } & 48 & Direito & Direito & Conc. com TR & SV \\
\hline & 70 & Direito & Esquerdo & Conc. com TR & SV \\
\hline Allard & 58 & Esquerdo & Esquerdo & Conc. com TR & SV \\
\hline Bozaci & 19 & Esquerdo & Posterior & 1 ano após nefrectomia & - \\
\hline Presente caso & 53 & Esquerdo & Posterior & Conc. com TR & SV \\
\hline
\end{tabular}

Conc. com TR: concomitante com o tumor renal; SV: sangramento vaginal; TR: tumor renal 
foram relatados e a maioria destes envolve metástases originadas do rim esquerdo. Isto já foi demonstrado com a injeção de contraste à veia ovariana esquerda, com enchimento subseqüente dos plexos ovarianos e vaginal, sendo consistente com a propagação venosa retrógrada ${ }^{4}$. É importante ressaltar que a metástase de carcinomas de células renais é do tipo sangüínea e que os principais sítios de metástases são pulmões (50\%) e ossos (33\%). Raramente ocorre metástase de carcinoma de células renais no olho e órbita, mimetizando outras lesōes ${ }^{5}$. As anastomoses entre o plexo útero-vaginal e a veia obturatória, que recebe ramos da veia genital externa, podem explicar metástase para a vagina distal. Entretanto, o modo mais provável de disseminação parece ser a por via venosa retrógrada o que explica a predileção metastática proveniente do rim esquerdo ${ }^{2}$. O diagnóstico da lesão genital geralmente precede e raramente ocorre após o diagnóstico da lesão renal. Os achados mais encontrados são: dor no flanco, sangramento vaginal e massa palpável ${ }^{3}$.

No histopatológico, é sabido que a expressão do CD10 no carcinoma de células renais e no sarcoma estromal de endométro é um marcador bastante útil nos diagnósticos diferenciais destes tumores, visto que inexistem outros marcadores confiáveis ${ }^{6}$. Desta forma, na imunoistoquímica, a metástase para o trato genital do carcinoma de células claras mostra constante positividade de CD10, enquanto que o tumor de células claras primário nessa região geralmente dá CD10 negativo, o que faz dele um importante meio para diagnóstico diferencial entre essas duas patologias ${ }^{6,7}$. Mas é importante que o achado deste marcador na lesão vaginal necessite de uma correlação clínica para determinação de seu local de origem, que foi determinado com a ultra-sonografia abdominal, demonstrando lesão incidental no rim esquerdo ${ }^{6}$. O tratamento consiste em nefrectomia radical seguida de excisão local e/ou radioterapia naquelas pacientes que apresentam apenas metástase vaginal ${ }^{2,4}$. No caso aqui relatado, foi realizada imunoterapia com interferon 2 posterior à nefrectomia radical e radioterapia devido à paciente apresentar metástases também para o fígado. Este é o tratamento padrão nos pacientes com metástase, podendo atingir um intervalo livre de doença prolongado em cinco anos e, raramente, até a cura. A imunoerapia com interferon $2 \mathrm{em}$ altas doses apresenta respostas objetivas ao redor de $15 \%$ que, mesmo sendo efêmera, ainda é de melhor resposta do que a quimioterapia citotóxica, que tem repostas em torno de $5 \%{ }^{8}$

O principal fator prognóstico dos carcinomas de células renais com metástase vaginal é saber se essa metástase se apresenta ou não isolada ${ }^{2,3,4}$. Metástases múltiplas, recorrentes e com envolvimento da veia renal são fatores adversos na sobrevida ${ }^{2,4}$. Entretanto, deve-se sempre ter em mente os demais fatores prognósticos já bem estabelecidos: arquitetura sarcomatóide do carcinoma renal, grau histológico nuclear, o tamanho do tumor e a presença de invasão microvascular intratumoral'.

\section{Declaração de conflito de interesse: nada a declarar}

\section{REFERÊNCIAS}

1. Perrone A, Gaggioli A, Di Renzo D, Arbizzani V, Emili E, Lo Cigno $M$, et al. Metastasi vaginale secondaria ad adenocarcinoma renale. Minerva Ginecol. 1997;49:405-407.

2. Bozaci EA, Atabekoglu C, Sertçelik A, Ünlü C, Ortaç F. Metachronous metastases from renal cell carcinoma to uterine cervix and vagina: Case report and review of literature. Ginecol Oncol. 2005;99:232-35.

3. Lialios G, Plataniotis G, Kallitsaris A, Theophanopoulou MA, Skoufi G, Messinis IE. Vaginal metastasis from renal adenocarcinoma. Ginecol Oncol. 2005;98:172-76.

4. Griffin SJ, Grainger R, Loftus BG, McDermott TED. Renal cell carcinoma presenting with vaginal metastasis. Ir Med J. 2003;96(4):115-16.

5. Tarraza HM Jr, Meltzer SE, DeCain M, Jones MA. Vaginal metastases from renal cell carcinoma: report of four cases and review of the literature. Eur J Gynaecol Oncol. 1998;19(1):8-14.

6. Chu P, Arber DA. Paraffin-section detection of CD10 in 505 nonhematopoietic neoplasms. Am J Clin Pathol. 2000;113(3):374-82.

7. Ordi J, Romagosa C, Tavassoli FA, Nogales F, Palacin A, Condom E, et al. CD10 expression in epithelial tissues and tumors of the gynecologic tract. A useful marker in the diagnosis of mesonephric trophoblastic, and clear cell tumors. Am J Surg Pathol. 2003;27(2):178-86.

8. Lopes A, Iyeyasu H, Lopes LF, Almeida ES, Castro RMRPS. Oncologia para graduação. São Paulo (SP): Tecmedd; 2005.

9. Dall'Oglio M, Srougi M, Ortiz V, Nesrallah L, Gonçalves PD, Leite KM, et al. Carcinoma de células renais incidentais e sintomáticos: fatores patológicos e sobrevida. Rev Assoc Med Bras. 2004;50(1):27-31. 


\section{Abstract}

Metastasis from renal cell carcinoma to the vagina is rare, occurring mainly in post-menopausal women. The main prognostic factor is whether the metastasis is single or multiple. Few cases have been reported in the international literature, and the majority involves metastases from the left kidney. The authors present a case of renal cell carcinoma with metastasis to the vagina in a 53-year-old patient whose initial clinical presentation was a pedunculated mass with irregular edges on the posterior vaginal wall. The lesion was removed surgically and proved to be clear cell adenocarcinoma. Abdominal ultrasound showed an incidental mass in the left kidney, and left nephrectomy was performed. Immunohistochemical investigation proved the latter to be a primary renal cell carcinoma, with vaginal metastasis. The patient then received adjuvant radiotherapy to the vagina and pelvis. Eight months after initial treatment the patient received immunotherapy with interferon 2-alpha due to the appearance of a liver metastasis. Patient was alive 17 months after surgery.

Key words: Vaginal metastasis, Renal cell carcinoma, Clear cell adenocarcinoma 
